\title{
CERCA Y LEJOS DEL INDIO: CUATRO NOVELAS HISTÓRICAS DE TEMA INDÍGENA EN ANTIOQUIA $(1896-1993)^{*}$
}

\author{
NEAR AND FAR FROM AMERINDIANS: Four \\ Historical Novels on AMERINDian \\ Topic in Antioquia (1896-1993)
}

Juan Carlos Orrego Arismendi ${ }^{1}$

\begin{abstract}
Artículo derivado de la investigación "La novela de tema indígena en Antioquia: caracterización y proceso histórico", financiada por el codi de la Vicerrectoría de Investigación de la Universidad de Antioquia en la Convocatoria Ciencias Sociales, Humanidades y Artes 2016 (código del proyecto: 2016-12871).
\end{abstract}

Grupo de Investigación y Gestión sobre Patrimonio, Departamento de Antropología, Facultad de Ciencias Sociales y Humanas, Universidad de Antioquia, Calle 70 \# 52-21, Medellín, Colombia.

Cómo citar este artículo: Orrego Arismendi, J. C. (2019). Cerca y lejos del indio: cuatro novelas históricas de tema indígena en Antioquia (1896-1993). Estudios de Literatura Colombiana 45, pp. 13-30. DOI: https://doi.org/10.17533/udea.elc.n45a01

juan.orrego@udea.edu.co

Universidad de Antioquia, Colombia

Recibido: 14.02 .2019

Aprobado: 24.04.2019

Copyright: $\odot 2019$ Estudios de Literatura Colombiana. Este es un artículo de acceso abierto distribuido bajo los términos de la Licencia Creative Commons Atribución No comercial - Compartir igual 4.0 Internacional
Resumen: en el amplio corpus de la novela latinoamericana de tema indígena, diverso temática y formalmente, pueden establecerse periodos y procesos regulares que dejan clasificar y relacionar algunas obras de modo inteligible. En el caso antioqueño, el estudio concentrado de cuatro novelas históricas deja ver -cuando se las observa en su sucesión cronológica- las diversas maneras en que el mito se funde con la narración histórica. Esa evolución se traduce en un proceso de acercamiento gradual al universo indígena que, sin alcanzar su culminación, deviene en alejamiento.

Palabras clave: novela antioqueña; novela histórica; indigenismo; heterogeneidad.

\begin{abstract}
In the broad corpus of the Latin American novel of Amerindian topic, diverse not only thematically but also formally, regular processes and established periods allow us classifying and relating some works in an intelligible manner. In the case of Antioquia, the concentrated study of four historical novels reveals - when analyzed in their chronological succession - the various ways in which myth emerges with the historical narrative. This evolution results in a process of gradual approaching to the Amerindian universe that without reaching its culmination, becomes in moving apart from it.
\end{abstract}

Keywords: antioquian novel; historic novel; Indigenism; heterogeneity. 


\section{Introducción}

La novela de tema indígena escrita por antioqueños se materializa en un corpus variopinto. Mientras que El Dorado (1896), de Eduardo Posada, se pliega al canon romántico latinoamericano, El valle de los perros mudos (2000), de Juan Gil Blas, se alinea en la corriente de la Nueva Novela Histórica descrita por Seymour Menton (1993). Otras obras, como Toá. Narraciones de caucherías (1933), de César Uribe Piedrahita, y Andágueda (1946), de Jesús Botero Restrepo, se concentran en la explotación del indio selvático en el contexto del extractivismo. El mosaico literario también incluye un folletín sentimental y antindigenista como Lejos del nido (1924), de Juan José Botero; una aventura de viaje por países suramericanos como la que hay en Motilonia o Andanzas de un antioqueño (1934), de Salvador Tello Mejía, y - entre otras obras - un zurcido de mitos amerindios como el conformado en Los abuelos de cara blanca (1991), de Manuel Mejía Vallejo.

Esa diversidad de novelas producidas en la región corresponde, en pequeña escala, al estado de cosas de la novela colombiana de tema indígena, la que a su vez refleja el mismo fenómeno literario en América Latina. Pero ese orden de cosas no implica que el subgénero novelesco en cuestión se haya manifestado con una multiplicidad de formas y temas tan irremediable como caótica. La crítica especializada ha mostrado que en medio del universo de las novelas son susceptibles de ser reconocidos algunos periodos o procesos (Sánchez, 1976; Cornejo Polar, 2005; Escajadillo, 1994; RodríguezLuis, 2004). Y lo llamativo es que reflexiones útiles - por su capacidad de aplicarse al ámbito continental - han nacido de estudios sectorizados: Tomás Escajadillo (1994), por ejemplo, se concentró en varias décadas de producción narrativa en el Perú para establecer los periodos del indianismo, el indigenismo y el neoindigenismo, extrapolables para indagar en el caso global latinoamericano, según lo prueba la reflexión mucho más reciente de Julio Rodríguez-Luis (2004). La implementación de marcos de pequeña escala - como el regional - para estudiar la literatura de tema indígena, antes que suponer el riesgo de tomar entidades político-administrativas como ámbitos naturales para la gestación de fenómenos literarios, puede significar la oportunidad de filtrar corpus de otra manera inabarcables y concentrar la mirada sobre algunos hechos significativos, de otra manera ininteligibles.

Este artículo se interesa en un subconjunto de novelas antioqueñas de tema indígena, en el que establece los rasgos de un proceso regular que lo afecta y que permiten pensarlo como una unidad legítima de estudio. Se 
trata de examinar cuatro novelas históricas de tema indígena distribuidas a lo largo de un siglo - las ya mencionadas El Dorado y Los abuelos de cara blanca, a las que se suman Curibaná (1977), de Álvaro Legretti, y Sueños epifanías y porros del continente eterno (1993), de Heriberto López Pérez-, atendiendo a que, al considerarlas en orden cronológico, se revela entre ellas una relación dinámica que explica algunas de sus características formales y discursivas. En pocas palabras, se trata de establecer y caracterizar un proceso literario que se desarrolla en ese subconjunto y que puede describirse como un gesto gradual de acercamiento al universo indígena; un gesto que, sin alcanzar su plenitud, se trueca por el contrario movimiento de alejamiento del referente.

A continuación presentamos un marco conceptual integrado por la reflexión de Antonio Cornejo Polar sobre el carácter heterogéneo de la novela de tema indígena, subgénero que el crítico entiende caracterizado por la oposición de la perspectiva cultural del escritor occidental y las maneras propias del universo indígena representado.

\section{Heterogeneidad de la novela de tema indígena}

Muy temprano, la crítica de la novela de tema indígena estableció la expectativa de que esa literatura habría de revelar, en algún momento, el alma o espíritu del nativo. José Carlos Mariátegui advirtió, en 1928, que el indigenismo no podía mostrar al indio tal cual era, pues se trataba de una "literatura de mestizos" que, necesariamente, carecía de "autoctonismo integral” y que por eso no podía interpretar y expresar al personaje amerindio sin recurrir a "elementos de artificio" (Mariátegui, 1976, p. 335). El ensayista señala un momento indefinido del futuro en el que habrá de consolidarse una literatura que no sea apenas sobre el indio, sino que sea propiamente indígena: "Una literatura indígena, si debe venir, vendrá a su tiempo. Cuando los propios indios estén en grado de producirla" (p. 81).

Los trabajos de Luis Alberto Sánchez, Tomás Escajadillo y Julio Rodríguez-Luis han seguido la senda señalada por Mariátegui, toda vez que han establecido una serie de periodos de la novela de tema indígena en la que se traduce un paulatino acercamiento a la realidad antropológica del nativo americano. Para Sánchez (1976), en la transición de los siglos XIX y XX se marcó la separación entre una literatura indianista de sesgo histórico y sentimental, en la que el personaje aborigen era "decorativo" y exótico, y el indigenismo propiamente dicho, en el que prima un "sentimiento de reivindicación social” (pp. 494-495). Escajadillo (1994) recoge esa 
sugestión a la hora de establecer la serie de tres periodos con que entiende el proceso histórico de la narrativa peruana de tema indígena: el indianismo decimonónico, hispanófilo y catequizante, y por ende situado en las antípodas de la verosimilitud etnológica; el indigenismo ortodoxo, que iniciaría con los Cuentos andinos (1920) de Enrique López Albújar (Escajadillo, 1994, p. 43), en el cual se implementan una perspectiva de proximidad etnográfica y un sentimiento de reivindicación del indio; y el neoindigenismo, expresión que se manifestó desde los años cuarenta y en la cual la creación literaria se apropia del mito, y potencia con ello su lirismo. Esta sucesión de maneras de dar cuenta de lo indígena traduce un gesto de acercamiento antropológico: se parte de una imagen muy falseada del nativo y se llega a los materiales mismos de su cosmovisión. No contento con el grado de madurez antropológica alcanzado por esa vía, Rodríguez-Luis (2004) todavía superpone un periodo final para el caso de la literatura latinoamericana: la narrativa testimonial en la que, con la mediación de un editor-etnógrafo, es la voz propia del indio la que cuenta sus propias historias. Ese tipo de obras habría dominado la escena en la segunda mitad del siglo $\mathrm{xx}$.

Antonio Cornejo Polar, en su estudio de 1980 sobre la novela indigenista peruana, pone el énfasis en la heterogeneidad de los elementos que conforman la narrativa sobre el indio desde su surgimiento en la Conquista; una tradición literaria que él etiqueta unitariamente como indigenismo, por creer que en ella subyacen siempre unos mismos elementos constitutivos, más allá de los grados de intensidad de su manifestación. Ese indigenismo reconoce, como condición de existencia, una brecha visualizada desde dos tipos de conciencia: una estructural (en el sentido lingüístico) que opone el "universo indígena" al "universo desde el cual el indigenismo es producido", y que se mantiene vigente como diferenciación sin importar el modo en que se defina cada entidad en un momento determinado; escribe Cornejo Polar (2005):

Ciertamente la magnitud y hasta la naturaleza de esta distancia entre lo indígena y su expresión indigenista pueden cambiar históricamente, tanto en el ámbito de la realidad [...] cuanto en lo que toca a su conceptualización [...], pero en ningún caso puede desaparecer. Si esto sucede, en un hipotético futuro de integración nacional, el indigenismo perdería de inmediato su base de sustentación (p. 35).

La otra conciencia remite a la realidad sociocultural, y es la que verifica que una sociedad capitalista y moderna, preponderantemente 
urbana y cuya cultura es de filiación occidental, "da razón” de una sociedad nativa, más o menos feudal - “incipientemente capitalista”- e inscrita en un orden cultural "mágico" (p. 36). Es claro que, más allá de la imagen promovida por la conciencia que construye la representación, el mundo referenciado no se dispone, en ningún sentido, como una yuxtaposición evolucionista de estratos sino como una contienda permanente en la que ambos pugnan por conservar sus "peculiaridades distintivas" (Cornejo Polar, 1978, p. 17).

Ahora bien, esa heterogeneidad no solo remite al contexto de producción de la literatura indigenista, sino también al producto mismo. Porque, muy a pesar de que la instancia productora controle el sistema y el código en que se ha de verter la obra - por ejemplo, que la inscriba en el género occidental de la novela y que la cifre en español-, y pese a que ella, por estar dirigida a un público urbano y letrado, circule al margen del universo indígena, es un hecho indiscutido que el referente sí corresponde a ese universo (Cornejo Polar, 2005, p. 54). Y ese elemento autóctono, al escapar al control total que se le quiere imponer por parte de la instancia productora occidentalizada, es el que "crea" la heterogeneidad al interior de la obra indigenista (p. 55). Un aporte sustancial de la reflexión de Cornejo Polar es la tesis de que el referente indígena, inserto en la novela indigenista, logra modificar en algún grado su molde occidental. El crítico se refiere a tres tipos de peculiaridad formal en que puede traducirse la influencia del referente indígena sobre el género novelístico: estructuras conformadas por relatos adicionados (como en el caso de las primeras novelas de Ciro Alegría); inserción de canciones y descripciones líricas del paisaje (como en la obra narrativa de José María Arguedas), y asunción de componentes míticos, ya sea que se relaten mitos o que se adopte su perspectiva o, para decirlo con más propiedad, el "pensamiento mítico" (p. 60), tal y como ocurre en Todas las sangres (1964), novela de Arguedas en cuyo desenlace se impone una perspectiva cósmica de fin de mundo y fundación de un nuevo orden. ${ }^{1}$

Para Cornejo Polar (2005), los mitos son los relatos que una sociedad tradicional emplea como "recursos" para "comprender o expresarse a sí misma", aunque acepta que algunas categorías míticas - como las secuencias apocalípticas - pueden ser universales, esto es, no constreñidas al mundo indígena (p. 61). Para completar este esbozo, adherimos a la reflexión de Joan Carles Mèlich (1996), para quien el mito es un "sistema dinámico de símbolos" que, materializado en relato, promueve valores comunitarios relacionados con el orden cósmico, la historia, la sociedad y el sentido de la vida; una función que se cumple en todas las sociedades humanas, con independencia de los tipos de relato puestos en juego (pp. 72-74). Para Claude Lévi-Strauss (1994) - quien siempre reconoció para el mito un irreductible eclecticismo formal-, el relato histórico en Occidente, cuyo modus operandi es la reducción simbólica de la experiencia, puede entenderse como un mito al servicio del valor de la historicidad, "último refugio de un humanismo trascendental" (p. 380). 
Antonio Cornejo Polar, es cierto, se acerca al optimismo de los críticos ya mencionados al establecer que hubo en Perú un indigenismo en “plenitud": el que, a partir de la cuarta década del siglo xx, se materializó en la producción narrativa de Alegría y Arguedas. Pero, a diferencia de sus pares, Cornejo Polar no piensa que esa literatura signifique un clímax en términos de lo indígena como expresión dominante: si el crítico habla de plenitud, lo hace porque reconoce en esas obras la expresión de la heterogeneidad característica de la corriente a la que pertenecen. Y es en la relación que, en las novelas de esos escritores peruanos, se establece entre el mito nativo y la historicidad de la narrativa occidental, donde mejor se expresa esa cualidad heterogénea; porque, en virtud de un doble "movimiento", mito e historia conforman una "unidad dialéctica dentro de la cual interactúan de manera harto sutil y compleja” (Cornejo Polar, 2005, p. 61); y, así, mientras el mito se ve obligado a historificarse para tomar parte en un ámbito novelesco, la historia se amalgama con la imaginación mítica para reemplazar el mundo ancestral que yace irremediablemente perdido bajo la coyuntura moderna. Refiriéndose a lo que ha sucedido en Perú, Cornejo Polar escribe que Alegría y Arguedas asumen la historia "para imaginar otro proceso y otro curso: el de la liberación del pueblo indígena” (p. 64).

De cara a nuestra propuesta, interesa no perder de vista estas ideas: la novela de tema indígena, aunque pretenda acercarse al nativo, no lo consigue en el sentido de alcanzar o expresar un universo indígena incontaminado. El sustrato antropológico de esta novela no es otra cosa que una situación de heterogeneidad sociocultural en la que lo indio es, apenas, una parte en relación con otra. Buena parte de los elementos indígenas que participan de esa conformación compleja son formas y modos narrativos entre los que el mito ocupa un lugar importante, ya sea porque modifique las formas y discursos literarios occidentales o porque él mismo se modifique albergándolos. Con el mencionado grupo de novelas históricas antioqueñas de tema indígena aspiramos a ilustrar esas tesis.

\section{Del indio historificado al indio historiador}

El Dorado (1896), de Eduardo Posada (Medellín, 1862-Bogotá, 1942), enmarca su anécdota en los hechos de la fundación de Santafé de Bogotá, llevada a cabo por Gonzalo Jiménez de Quesada. La india "chibcha" Zoratama y el conquistador Lázaro Fonte viven un idilio en medio de la coyuntura del destierro de Fonte a Pasca, confinado allí por orden del 
fundador. Tras la muerte de Fonte, ocurrida años después en tierras de los indios quitos, Zoratama y un hijo abandonan el altiplano y van hasta la laguna de Guatavita. Allí, por decisión de la mujer, ambos se sumen fatalmente en las aguas, y actualizan así la imagen central de una leyenda local narrada en el segundo capítulo de la obra.

El Dorado pertenece a una época en que la creación literaria apelaba a la reescritura de fuentes documentales, con dominio de la perspectiva y las maneras de la narración histórica. Varios indicios así lo prueban, entre ellos la estructura lineal de la novela, dispuesta como la sucesión cronológica de los principales episodios del descubrimiento de la sabana de Bogotá y de la fundación de la ciudad; porque, si bien el capítulo II - "Los chibchas" - sucede en un tiempo que puede entenderse como simultáneo o incluso anterior a los hechos narrados en el primer capítulo - "Los hijos del Sol”-, esto es así solo porque se adopta una perspectiva hispánica: tras contar cómo los españoles remontaron el río Magdalena y llegaron al altiplano cundiboyacense, el narrador ofrece, antes de relatar el avance de los conquistadores por la Sabana, un paréntesis etnológico sobre quiénes eran y cómo vivían los nativos de ese lugar. De ese apego histórico hablan también los epígrafes que se anteponen a cada capítulo, extractados todos ellos de crónicas de Indias, tratados de historia y geografía o poemas de tema histórico, caso, este último, de una estrofa de las Elegías de varones ilustres de Indias, de Juan de Castellanos, y de un fragmento del poema "Les Conquérants de l'Or”, de José-Maria de Heredia Girard. El novelista sugiere su plegamiento pasivo a esas obras cuando, en una nota sobre su novela, escribe que "El Dorado es un pedazo de historia más bien que cuento" y agrega que "No hay allí nada novelesco sino el fin de los dos héroes" (Posada, 1896, p. x). Sobre Lázaro Fonte, advierte Posada, no se sabe con exactitud en qué circunstancias murió, mientras que no hay noticia, en las fuentes históricas, de ninguna mujer llamada Zoratama: el escritor tuvo que "dar nombre á la india, pues lo callan nuestros cronistas" (pp. X-XI). Lo único establecido en los documentos de referencia - concretamente, en la Conquista del Nuevo Reino de Granada de Lucas Fernández de Piedrahitaes la imagen borrosa de una mujer que acompañó a Fonte durante su confinamiento en Pasca (p. 146).

Aparte de lo anterior, también el discurso novelesco revela abiertamente de qué tipo de fuentes bebe y la recepción que hace de ellas. Al iniciar el capítulo vi, por ejemplo, el narrador deja ver con claridad que 
acomete un trabajo de reescritura de los documentos históricos: “Oíd cómo cuenta la historia que pasó la odisea del capitán Fonte, el infeliz desterrado por Jiménez de Quesada, en los yermos de Pasca, entre indios salvajes y fieras carnívoras" (p. 177). En un pasaje sobre la marcha de un contingente español hacia el norte y oriente de la sabana, el mismo narrador ya había hecho una valoración superlativa de la materia de su escritura: "la pluma se fatiga al referir tántos episodios maravillosos" (p. 147). Así pues, los textos históricos no solo ofrecen material abundante a la novela, sino que, por su rutilancia épica - son "maravillosos" y propios de una "odisea" -, son la fuente más adecuada. De hecho, la aventura que se relata en la novela es, literalmente, la de quienes escriben la historia: desde el primer capítulo se informa que en la hueste de Quesada iba Fernández Gironda, quien "hablaba de la fundación de Cartagena, en la cual había acompañado á Heredia, y cuya historia tenía escrita" (p. 98). Asimismo, por medio de uno de los epígrafes del capítulo III se extiende el atributo de la escritura hasta el fundador: allí, tras verterse unas líneas de la Epítome de la conquista del Nuevo Reino de Granada, se informa que se trata de un texto "atribuído á Quesada" (p. 123).

El predominio de la textualidad histórica tiene hondas implicaciones en la plasmación de los personajes indígenas. Por un lado, ocurre que a los nativos, entendidos como opuestos de los españoles letrados, corresponde el estatus de los animales salvajes: en el abrebocas de la novela, cuando se detallan los peligros que habían afrontado los conquistadores en las selvas del Magdalena, se ofrece un inventario que incluye "cocodrilos", "insectos y reptiles venenosos", el "tigre", el "crótalo" e "indios feroces y pobres" (p. 90). En lo sucesivo, la obra será recorrida por alusiones al salvajismo o barbarie de los nativos. Esta clasificación discriminatoria, empero, no pasa de ser un tópico en la novela de tema indígena en general — no solo de la modalidad histórica decimonónica-, y por eso resulta mucho más significativa la manera como el mito muisca es apropiado por la reescritura histórica. Tras haber sido referido, en el capítulo II, el relato ancestral de la cacica que, junto con su hija, se sumergió en la laguna de Guatavita, el capítulo final reitera el motivo en la persona de Zoratama, quien, desterrada y separada irremediablemente de Fonte, va hasta el mismo paraje y, con su hijo, se tira a las aguas. Se trata de una manifestación nítida de la historificación del mito en términos de Cornejo Polar, porque, además de que el motivo mítico es introducido como un eslabón más de la secuencia de hechos históricos, se lo pone allí donde, precisamente, el relato histórico acusaba un vacío. 
En Curibaná (1977), de Álvaro Legretti (seudónimo de Heliodoro Rojas Olarte: Santa Rosa de Osos, 1932-Medellín, 1991), se agrupan los mismos elementos pero con diferentes matices. La novela se interesa en la resistencia del pueblo nutabe frente a las avanzadas de los conquistadores españoles. El cacique Curibaná participa en una primera batalla victoriosa contra Francisco Vallejo, en 1541, y tres décadas después, con el apoyo de sus hijos, en la refriega en que resulta vencida la hueste de Andrés Valdivia. En el ínterin tiene lugar uno de los principales hechos de la novela, y es que los nutabes se entretienen narrándose los principales hechos de la conquista en Antioquia, de los que tienen un conocimiento casi omnisciente. Tras la batalla contra Valdivia, Ochalí se presenta ante su padre Curibaná para informarlo del triunfo, pero ambos son asesinados por un hechicero traidor. El cacique se convierte en humo, y por él asciende su hija Cliceyé, quien al final se reduce a ser una voz que maldice al hechicero por haber colaborado con los españoles y le anuncia que en el futuro triunfará una sociedad igualitaria.

Los amplios recuentos históricos de los narradores indígenas son tan profusos y exactos en sus referencias a fechas, lugares y personajes, que se puede colegir que también en este caso ha mediado, por parte del escritor, un prolijo trabajo de investigación en archivos históricos. El brujo Jedeco, en una reunión de la comunidad nutabe, cuenta: "Cuatro viajes realizó Colón de 1492 a 1505, en los cuales reconoció los litorales y dejó las fundaciones que requería en los antes dominios de Guanahaní, Haití, Borinquen, Jamaica, Cubaga, Chiriquí y el propio golfo del Darién" (Legretti, 1983, p. 28). Inclusive, una marca discursiva sugiere que la apropiación de esa voz documental ha sido tan completa que los personajes nutabes hablan como los cronistas españoles: en la alocución referida — un ejemplo entre muchos-, Jedeco exhorta así a su pueblo: "Y me preguntareis ¿por qué avanzan con tal celeridad, seguridad y bravura?” (p. 28). Nótese, además de la barroca enumeración de sustantivos, el uso de la segunda persona del plural, tan característico del castellano peninsular.

Ahora bien: ¿por qué, a pesar de esa alta deuda con las fuentes históricas hispánicas, no se hace explícita la identidad de sus autores? Quizá ocurre que, a diferencia de lo que pasa en El Dorado, el narrador de Curibaná no quiere autorizar su escritura vinculándola con los nombres de los letrados españoles. Su pretensión, opositora, es usurpar el saber 
histórico y situarlo como un saber indígena. Al respecto es significativo lo que el pueblo nutabe, al analizar la proximidad de la hueste de Vallejo, expresa a modo de protesta: "La historia ya la sabemos" (p. 19). Más adelante, Cliceyé encomiará el relato de la campaña de Francisco César hecho por su hermano Quimé: “Te expresas bien, hermano. Eres objetivo y no has olvidado detalle" (p. 109). De modo que si los nutabes usan una dicción española, ello no se debe a que los haya hispanizado la perspectiva occidental del narrador omnisciente, sino a que se han apropiado del rol del historiador y cuentan la historia bajo un código especializado. Un argumento adicional a favor de la tesis de la usurpación del saber histórico es que, en los parlamentos nutabes, una de las pocas referencias intertextuales explícitas — si no la única - es a "Maín” (p. 104) y a "Miguel Ángel Osorio" (p. 184), respectivamente uno de los seudónimos y el nombre de pila de quien fue más ampliamente conocido como Porfirio Barba Jacob, poeta y narrador nacido en Santa Rosa de Osos, esto es, en la misma región en que transcurren los hechos de la novela.

La referencia a Barba Jacob es importante en nuestra interpretación, toda vez que está ligada a la inclusión del mito. La esposa de Curibaná lleva el nombre de Acuarimá, que es una suerte de apócope de "Acuarimántima", título del poema en que el poeta de Santa Rosa se identifica, precisamente, como Maín: "Yo soy Maín, el héroe del poema" (Barba Jacob, 1983, p. 67). Se sabe de esta Acuarimá que no es nutabe y que llegó a la comunidad para asumir el papel de heroína civilizadora, tal como lo reconoce Curibaná: "Ella nos enseñó a sazonar con fuego los alimentos, a labrar la tierra y a sembrarle papas, arracachas, y maíz, a preparar la chicha apetitosa y buena, a tejer las anteas y las mantas de algodón, a construir las casas" (Legretti, 1983, p. 56). A todas luces, se trata del trasunto de un mito fundacional; una sugestión que se ve reforzada por una sospecha expresada por Jedeco, quien tiene para sí que Acuarimá era antes la luna (p. 27). Ahora bien, es significativo que la mujer se oponga a esa tesis y ofrezca una explicación racional de su periplo: aunque remoto, identifica su lugar de procedencia como una "aldea kolla" (p. 52), y aclara que, si los nutabes la vieron emergiendo de las aguas, ello fue porque, cansada de viajar desde el sur, se había metido al lago para relajar sus músculos. Su perspectiva secularizadora es evidente: "Continuó diciendo Acuarimá, que ella misma, como Bachué o como Dabeiba la catía, como Achachila, o Chibchacum, no han sido más 
que seres humanos que han dejado sus lugares de origen por una razón $\mathrm{u}$ otra, $\mathrm{y}$ han emigrado a pueblos cercanos o lejanos, donde han podido establecerse" (p. 52). Así que también en la novela de Legretti, el mito ha sido incluido en la narración histórica y esta lo ha historificado. Pero, además de eso, la narración también ha incluido un mito occidental: no otra cosa significa una ilusión comunista que recorre la obra, manifiesta en un discurso antioccidental puesto en boca de los nutabes y pletórico de consignas, entre las que llama la atención una expresión proferida por los indígenas en situación de enfrentar a Valdivia: "Nutabes de todos los caseríos; uníos" (p. 201), clara parodia de la famosa frase de exhortación a los proletarios del Manifiesto del Partido Comunista de 1848. Ese anhelo de la liberación de la humanidad es el mito histórico por excelencia, motivo que, como quedó citado atrás, Antonio Cornejo Polar ve aflorar en los desenlaces de Arguedas y Alegría, donde toda tesis se traduce en la necesidad de conseguir la "liberación del pueblo indígena".

Hay, entonces, una intensificación de la presencia mítica en la novela de Legretti, pues además de los dos mitos mencionados, todavía habría que considerar si el desenlace, en el que Cliceyé sube al cielo por un eje vertical -la columna de humo en que se convierte Curibaná-, no debe algo al corpus de la mitología suramericana. Como quiera que sea, tal presencia mítica, aunque historificada, deja sentir sobre la narración histórica un influjo más apreciable que en el caso de El Dorado, donde el mito actualizado había sido acomodado, simplemente, en el orden narrativo lineal. Ese orden ya acusa alteraciones en Curibaná, según lo dejan ver dos indicios: uno de ellos es que los personajes nutabes relatan la historia sin plegarse al orden cronológico, como si sus episodios fueran intercambiables: Cliceyé, ante el ruego de sus hermanos de que les hable de las guerras entre nativos y españoles, construye una serie narrativa conformada por el enfrentamiento entre Malchina y Núñez Pedroso en 1546, la lucha de Penco y otros caciques contra Robledo en 1536, la campaña en 1574 de Tejelo contra bitagüíes y aburráes, y la muerte de Nuquío en 1547 por orden de Gaspar de Rodas (pp. 104-105). El otro indicio es el que, precisamente, liga el contenido mítico con la alteración narrativa, y son las alusiones anacrónicas - por anticipación - a Barba Jacob: "Aquí nacerá Maín, profeta de la paz y adalid de la justicia", anuncia Cliceyé antes de tratar el tema bélico con sus hermanos (p. 104). De esa manera, el pasado, el presente y el futuro llegan a confluir en un mismo episodio. 


\section{Del mito a la simulación}

Los abuelos de cara blanca, de Manuel Mejía Vallejo (Jericó, 1923-El Retiro, 1998), representa algo muy cercano a la apoteosis del mito amerindio. La novela es un mosaico de mitos - con inclusión de cuentos y cantos ancestrales- de diversas culturas, y consecuencia de ello es que no se siga la historia lineal de un protagonista, como no sea la difusa vivencia de Antel, un soñador cuyas figuraciones oníricas acaban cobrando vida propia mientras él se convierte, a su vez, en sueño. La mayor parte de la novela es la conversación de las figuras soñadas: la pareja conformada por Idlar y Nam Yavarí, el mestizo Juan Paramuno, una voz rebelde anónima y muchos personajes étnicos antonomásticos, entre los que se destacan El Katío, El Azteca, El Inca y El Chibcha. Estos personajes alternan sus relatos y recitaciones ancestrales siguiendo una lógica temática orientada por la libre asociación de ideas y motivos. El capítulo IV, por ejemplo, está compuesto por parlamentos sobre el descubrimiento y producción del fuego atribuidos a varios personajes -incluido Antel-, con intercalación de otros relatos sobre el diluvio, la noche y el amor. Otro rasgo relevante de esa sucesión de narraciones ancestrales es que no tiene en cuenta el criterio cronológico: el capítulo III, por ejemplo, invoca asuntos como los nombres de las cosas y el hábito de llorar a los muertos, y por ello es intercambiable con el capítulo del fuego; asimismo, el tema del origen de las cosas y los seres se trata en el primer capítulo y reaparece en el noveno, sin estorbar que, en el interregno, haya sido abordado el tema de la Conquista desde las diferentes voces, incluida la de Juan Paramuno.

Esa figura de Paramuno - un mestizo contador de historias- se revela importante en el contexto de la relación entre mito e historia. Es en su primera intervención en la conversación multiétnica cuando este personaje se refiere a hechos de la Conquista; concretamente, al pasmo de los indios ante la parafernalia española: "algunos se asustaron al recordar el tiempo invasor de los dioses rubios 'que sólo tenían humo y oscurana en el corazón', y de las carabelas, fabulosas islas flotantes y de los centauros de armadura, dueños de la chispa y del trueno matador" (Mejía Vallejo, 1991, p. 80). El carácter híbrido del personaje - llega a decirse de él que es "el descendiente de todo y de nada, el mestizo total" (p. 81) - se refleja en la complejidad de su imagen de la invasión española, en la que echa mano tanto de una perspectiva nativa - pensar a los ibéricos como a dioses o a sus barcos como islas - como de tópicos occidentales - la metáfora de los centauros-. Sin embargo, lo que más importa en ese relato y otros 
del mismo tema es que representan la narrativa histórica: una modalidad narrativa que viene a insertarse de modo fragmentario y episódico en una narración dominada por un régimen narrativo mítico. De modo que si en las novelas anteriormente consideradas el mito es absorbido y más o menos sometido al parámetro lineal de la narrativa histórica, en Los abuelos de cara blanca parece que fuera la historia la que es puesta en función de la lógica del discurso nativo, cuyos modos de expresión y evolución son acronológicos y circulares. Incluido en el fresco narrativo de la novela, el choque de América y España no es algo que haya sucedido una sola vez - amarrado a una fecha-, sino algo que ocurre ininterrumpidamente. $\mathrm{Al}$ respecto, llama la atención que Paramuno, en otra de sus intervenciones, se refiera a la conquista de la Sabana de Bogotá citando un texto cuyos verbos están en tiempo presente: "ocurre la muerte de Juan Gordo, soldado de Quesada condenado por el supuesto delito de hurto a los indios. Los Muiscas observan que los españoles mueren lo mismo que ellos" (p. 126).

Puede decirse que Los abuelos de cara blanca, por su estructura, su discurso y sus fuentes, es la novela antioqueña - incluso colombiana- que mejor ilustra la expectativa de Cornejo Polar de que el referente indígena, al ser incluido en el sistema literario occidental, modifica con su "fuerza" el canon productivo. Con intensidad, esa obra materializa las posibilidades de inscripción del mito en la novela, que de acuerdo con el crítico son varias y van "desde la mención referencial a ciertos mitos indígenas, o a componentes parciales de ellos, hasta la apropiación del pensamiento mítico propiamente tal como elemento constitutivo de la perspectiva de la novela" (Cornejo Polar, 2005, p. 60). No obstante, a pesar de haberse alcanzado ese punto de máxima cercanía respecto a una "verdadera" perspectiva o cosmovisión indígena, o, si se quiere, a una experiencia antropológica propiamente dicha, el objeto encontrado no deja de ser una conformación heterogénea. Aunque los temas y lógicas del mito amerindio rigen sobre la forma de la narración en Los abuelos de cara blanca, ese mito no puede evitar transformarse a su vez: en efecto, ha sido puesto por escrito en una lengua ajena, e incluso -las veces en que no se transcriben textualmente los documentos acopiados en el proceso creativo - ha sido plasmado con arreglo a la lengua estilizada del novelista. Además de eso, cada mito ha sido acomodado en un vitral mitológico multicultural que, a fin de cuentas, es también un artificio, toda vez que se pliega al sentido de la colección de museo, que es otra de las maneras occidentales de representar la historia. Las últimas líneas de la 
novela reivindican, precisamente, ese discurso: "En esta forma cuentan la historia quienes de verdad la saben” (Mejía Vallejo, 1991, p. 263).

Los anacronismos y la fragmentación episódica son, también, rasgos notorios de Sueños epifanías y porros del continente eterno (1993), novela de Heriberto López Pérez (Remedios, 1944) en que se distinguen dos historias contadas de modo alternado: la confrontación entre algunas naciones amerindias - nutabes, aburráes, hebexicos, tahamíes, cunas, chamíes y catíos, entre otras - y los conquistadores españoles en el siglo XVI; y la vida en Medellín en la segunda mitad del xx, dispuesta en una serie de relatos que, en parte, incluyen como personaje al cacique Nutibara, quien surge en los tiempos modernos por obra de un conjuro. A un lado de estos dos hilos narrativos se intercalan otros relatos independientes - algunos de ellos, cuentos propiamente dichos-y largos periodos muy cercanos al juego de palabras. Varios narradores participan del relato, uno en tercera persona con visos de omnisciencia, y otros, indeterminados, en primera persona.

Las características formales de Sueños epifanías y porros del continente eterno expresarían una posición crítica frente a la precisión de la escritura histórica, explicitada en algunos pasajes de la novela; por ejemplo, a Arturo Medicina - protagonista de uno de los fragmentos medellinenses- se le atribuye la idea de que "Es el poder de lo imaginario lo que forma la historia, dándole memoria y creencia” (López Pérez, 1993, p. 241), reforzada más adelante con la reflexión de que solo la ficción logra decir lo que "se nos ha ocultado en nombre de la historia” (p. 243); mucho antes, el narrador omnisciente había consignado la advertencia de que el cacique Nutibara, "de caer en una novela", se introduciría en la historia (pp. 30-31). Hay, pues, una valoración escéptica de la narración histórica, a la que se entiende como opositora -o deudora - de un discurso alternativo, en este caso la ficción; de hecho, hay un guiño muy claro a la novela histórica de tema indígena, entendida como la que puede hablar con "realidad" de una figura como Nutibara. Coherente con eso, la novela se abre con una dedicatoria a dos indios "caídos", Luis Napoleón Torres y Ramón Emilio Arcila, y en muchos pasajes recurre a un discurso indigenista, como un pasaje tipo monólogo, de la segunda parte, en que se repudia la explotación esclavista y el abuso físico del indio desde la Conquista (p. 162); además, la experiencia de Nutibara en Medellín se traduce en la convicción, por parte del cacique, de que los habitantes y cosas del valle del Aburrá son continuidad de la humanidad y la tradición amerindias. 
De cara a lo anterior, $\dot{¿}$ cabe la posibilidad de que el discurso alternativo que se considera más verídico que la historia pueda ser, además de la ficción, el mito? Ello es plausible a la luz de la consideración de que los mitos son "el más alto grado de lenguaje" (p. 142), y de la referencia a los mitos embera de Dabeiba, creadora y nominadora de las cosas, y de Caragabí, originador de los temblores al pasarse el mundo de una mano a otra (pp. 125, 142). Sin embargo, esas alusiones míticas son fugaces y se funden en el discurso novelístico: la corta alusión a Caragabí, por ejemplo, da paso a la noticia de un indio de apellido Vélez - notoriamente hispanizado- que adivina el advenimiento de hombres blancos y que da pie para que al discurso indígena se le identifique con el aire musical del porro (p. 125). De hecho, ya antes el narrador omnisciente había sobrepuesto la ficción al mito, al imitar sus formas retóricas en lo que no era otra cosa que un relato de su invención: "Antes de que el comienzo empezara ya el hombre había sido lo que era. Vivían en los árboles y comían fruta. De vez en cuando se comían unos a otros pero cuando aprendieron a soñar, con los sueños dejaron de comer la carne de los que estaban en las ramas bajas de los árboles" (p. 66). Así reza el comienzo de una historia que se ubica en un tiempo anterior al surgimiento del porro y que concluye cuando "Maraca" enseña a los hombres a bailar, lo cual fue "el origen verdadero" (p. 66). Se puede colegir entonces que si la ficción encierra más veracidad que la historia, también ha sometido al mito: este no participa realmente como "fuerza" o elemento estructurador de la novela, pues, por obra de la ficción, su estatus cultural es atribuido al porro, el cual se propone como el eje de la continuidad de la tradición amerindia: "La lengua de los Nutibaras es la lengua del porro" (p. 102), anota el narrador en la primera parte. En reemplazo de la palabra mítica ausente, la novela - sobre todo en su segunda parte, más cercana a la cultura de la Medellín contemporánea- está recorrida por anécdotas ligadas al ámbito social del baile del porro y a los temas plasmados en sus letras. En suma, la realidad del mito es suplantada por una metáfora.

Ese alejamiento del universo nativo también se patentiza en una contradicción respecto a la posición asumida ante la narración histórica; porque, a un lado del juicio adverso ya mencionado, la novela revela de modo explícito que ha recurrido a fuentes hispánicas para reconstruir algunos de los hechos de la invasión española y de la vida indígena antes de ella. No se esconde una predilección por la crónica de Pedro Cieza de León, de la cual se vierten no pocos pasajes textuales (pp. 13, 53, 59-60, 67). 
Una imagen proveniente de La crónica del Perú (1553), principal obra del cronista, es invocada una y otra vez en la novela: el suicidio de algunos habitantes del valle del Aburrá, quienes se ahorcaron con sus propias ropas cuando avistaron a los españoles (Cieza de León, 1984, p. 120). El suceso es puesto en boca de una mujer de Ebéjico, antigua novia de Nutibara y quien, como él, ha viajado en el tiempo y se reúne con el cacique en Medellín: "Ella contó la historia de aquel día amargo en que los Aburráes se habían ahorcado ante la visión de los Birríes" (López Pérez, 1993, p. 38). En lo sucesivo, se vuelve sobre el motivo varias veces, unas más explícitas que otras (pp. 44, 73, 95, 111, 188, 266). De modo que, incluso para surtir la denuncia indigenista, la novela recurre a la voz histórica, de la que elige una imagen con fuerza expresiva como para tornarse ritornelo literario. El triunfo de la ficción sobre la historia y el mito acabará expresándose en el discurso experimental y cifrado del autor, manifiesto a lo largo de la novela.

\section{A modo de conclusión: acercamiento y alejamiento del indio}

La novela latinoamericana de tema indígena - surgida con la anónima Jicoténcal (1826) — se ha desarrollado paralelamente a la disciplina antropológica, o por lo menos ha sentido su influjo desde que esta maduró como discurso especializado sobre la diversidad cultural. Ello significó que, conforme avanzó el tiempo, esa novela pudo acercase gradualmente al universo indígena y fue acrecentado su posibilidad de expresar una realidad etnológica propiamente dicha. Más allá de que críticos como Roberto González Echevarría (2000) hayan señalado lo característico que fue, de la narrativa latinoamericana del siglo $\mathrm{xx}$, nutrirse del archivo filológico $\mathrm{y}$ mitológico de la antropología, las mismas novelas aquí analizadas lo revelan: Manuel Mejía Vallejo (1991), en el introito a Los abuelos de cara blanca, pone de presente la "abundante documentación" (p. 5) sobre la vida amerindia a la que recurrió para escribirla, mientras que el narrador de uno de los fragmentos de Sueños epifanías y porros del continente eterno comenta - con respecto a varios asuntos de la Conquista- que "ahora se sabe cada vez más" (López Pérez, 1993, p. 162). Dado que el proceso de producción de la novela de tema indígena implica que alguien que no es el indio pretenda dar cuenta de él, esa expresión literaria está conformada de modo heterogéneo: algo propiamente indígena es incorporado por el sistema occidental de la novela, género que en algún grado se modifica por la "fuerza" de ese 
referente nativo. Es innegable que el mito, en tanto realidad lingüística, es la parte del universo indígena más susceptible de manifestarse en la estructura y discurso novelístico e influirlos hasta modificarlos a partir de las formas y temas canónicos. En la literatura antioqueña de los últimos 120 años, la aparición en 1991 de Los abuelos de cara blanca representa, muy probablemente, el punto de mayor acercamiento de la escritura indigenista a la referencia nativa: allí, el mito ha disuelto la linealidad y ha convertido el discurso sobre el pasado en un mosaico episódico de relatos ancestrales que sugieren la simultaneidad de los hechos que cuentan. Pero esa novela, amén de sus contenidos antropológicos relativamente genuinos -en todo caso, el mito ha sido historificado al ser vertido en la escritura-, cuando se la considera solo desde un punto de vista formal lo que se ve es una figura alternativa que subvierte la forma clásica de la narración novelesca, lineal y cronológica. De esa manera, una obra como Los abuelos de cara blanca, al apostar tan intensamente por el mito, lo que hace es fundar una asociación - o subrayarla - entre las formas literarias no convencionales y la expresión de lo otro cultural. En lo sucesivo, puede suceder que el tema indígena se plasme en una escritura que solo sea literariamente alternativa, sin serlo, necesariamente, en un sentido antropológico; dicho de otro modo: la ruptura antropológica de Los abuelos de cara blanca puede ser interpretada como licencia de ruptura radical per se: como si solo con romper lo hegemónico, no importa con qué recurso - así sea con la suplantación de la voz nativa por ficción simulada-, se lograra expresar plenamente el valor de otro de lo indígena. Esto último es lo que ocurre con Sueños epifanías y porros del continente eterno, donde una experimentación formal - un divertimento literario - sin mito de referencia - o mejor, que no ha alcanzado a recibir la refracción de un mito auténtico- asume la tarea indigenista de reivindicar al indio. Pero en realidad lo que ha hecho es empezar un gesto de alejamiento de esa referencia, si no es que ese tipo de propuesta representa en sí mismo el punto de mayor distancia respecto al universo indígena; porque, antes que expresar lo que se conoce de él, se ha optado por imaginarlo libremente. Entre las implicaciones que se derivan de esto, una - no menor- es que en Antioquia la producción de la novela de tema indígena supone lejana $-o$ radicalmente niega - la expectativa de Mariátegui de que el indio pueda hacerse cargo de su propia literatura; las novelas escritas después de 1993, que aquí no consideramos, parecen confirmarlo. 


\section{Referencias bibliográficas}

Barba Jacob, P. (1983). Obra poética. Medellín: Bedout.

Cieza de León, P. (1984). La crónica del Perú. Madrid: Historia 16.

Cornejo Polar, A. (1978). El indigenismo y las literaturas heterogéneas: su doble estatuto socio-cultural. Revista de Crítica Literaria Latinoamericana 4 (7-8), pp. 7-21.

Cornejo Polar, A. (2005). Literatura y sociedad en el Perú: la novela indigenista. Clorinda Matto de Turner, novelista. Estudio sobre Aves sin nido, Índole y Herencia [1980]. Lima: Centro de Estudios Literarios Antonio Cornejo Polar, Latinoamericana.

Escajadillo, T. (1994). La narrativa indigenista peruana. Lima: Amaru.

González Echevarría, R. (2000). Mito y archivo. Una teoría de la narrativa latinoamericana. México: Fondo de Cultura Económica.

Legretti, Á. (1983). Curibaná. Medellín: Sandino.

Lévi-Strauss, C. (1994). El pensamiento salvaje. México: Fondo de Cultura Económica.

López Pérez, H. (1993). Sueños epifanías y porros del continente eterno. Medellín: Ediciones Autores Antioqueños.

Mariátegui, J. C. (1976). 7 Ensayos de interpretación de la realidad peruana. Lima: Amauta. Mejía Vallejo, M. (1991). Los abuelos de cara blanca. Bogotá: Planeta.

Mèlich, J. (1996). Antropología simbólica y acción educativa. Barcelona: Paidós.

Menton, S. (1993). La Nueva Novela Histórica de la América Latina 1979-1992. México: Fondo de Cultura Económica.

Posada, E. (1896). “El Dorado”. En Viajes y cuentos (pp. 87-194). Bogotá: Imprenta de la Luz.

Rodríguez-Luis, J. (2004). Tercer avatar del indigenismo literario. En E. Mächler Tobar (Ed). Autour de l'Indigénisme. Une approche littéraire de l'Amérique latine (pp. 125140). París: Indigo, Université de Picardie Jules Verne.

Sánchez, L. (1976). Proceso y contenido de la novela hispano-americana [1953]. Madrid: Gredos. 